\title{
Aid and adaptation to climate change in Pacific island countries
}

\author{
Carola Betzold
}

\section{Abstract}

Pacific Island Countries (PICs) are already experiencing the adverse impact of climate change yet often lack (human and financial) resources to meet the challenges of changing climatic conditions.

This paper examines adaptation aid committed to recipient countries in the Pacific between 2010 and 2014 using data from the Organisation for Economic Cooperation and Development (OECD). Specifically, the analysis tracks how much adaptation aid flowed to the PICs, which countries and sectors received how much, and which bilateral and multilateral donors provided this aid. Although the analysis is only a first step towards a more detailed understanding of adaptation aid flows in the Pacific, some conclusions can be drawn. First, adaptation aid to PICs is only a small share of global adaptation aid as well as of total development aid to the region. Second, adaptation aid comes from only a small number of mostly bilateral donors, and is, third, distributed unevenly among PICs, in total adaptation aid, on a per capita basis as well as in percent of overall development aid. Finally, adaptation aid to the Pacific has steadily declined from a high in 2011, largely driven by Australia's considerable reduction in adaptation aid in the region.

Donors should not only provide scaled-up and more predictable support for adaptation in the Pacific; they should also ensure that the support reaches those most in need. Finally, donors should also improve reporting so that adaptation aid can be tracked and monitored more easily.

\section{Development Policy Centre Discussion Paper 46}

\section{JULY 2016}




\title{
Aid and adaptation to climate change in Pacific island countries
}

\author{
Carola Betzold ${ }^{1}$
}

Dr Carola Betzold is a Postdoctoral Research Fellow at the Institute of Development Policy and Management at the University of Antwerp in Belgium.

Betzold, C 2016 "Aid and adaptation to climate change in Pacific island countries," Development Policy Centre Discussion Paper \#46, Crawford School of Public Policy, The Australian National University, Canberra.

The Development Policy Centre is a research unit at Crawford School of Public Policy, The Australian National University. The discussion paper series is intended to facilitate academic and policy discussion. Use and dissemination of this discussion paper is encouraged; however, reproduced copies may not be used for commercial purposes.

The views expressed in discussion papers are those of the authors and should not be attributed to any organisation with which the authors might be affiliated.

For more information on the Development Policy Centre, visit: http://devpolicy.anu.edu.au

\footnotetext{
1 The author would like to thank Patrick D. Nunn, Matthew Dornan, Paul Mitchell and one anonymous reviewer for comments on earlier versions of this paper.
} 


\section{Introduction: Adaptation, Aid and Pacific Island Countries}

Pacific Island Countries (PICs), like other vulnerable countries, are already experiencing the adverse effects of a changing climate. Climate change amplifies other environmental and development challenges faced by the PICs (e.g. Lazrus 2012, Weir and Orcherton 2013). Adaptation - "the process of adjustment to actual or expected climate and its effects" (Agard and Schipper 2014) - is thus needed across the PICs.

To meet the costs of adaptation, outside assistance is important, not least from a climate justice perspective: after all, PICs have contributed minimally to global greenhouse gas emissions but are disproportionately affected by the adverse effects of climate change. The Intergovernmental Panel on Climate Change concludes that adaptation is "a significant financial and resource challenge" for small island developing states (SIDS), including the PICs (Nurse et al. 2014, p.1635). This is partly because adaptation costs in SIDS are relatively higher per capita due to the small size of their populations and territories, as well as due to the vast geography of the Pacific and the dispersed populations. ${ }^{2}$ While national governments provide significant co-financing, adaptation often depends on the availability of external funding; as Barnett (2005, p.214) writes, "adaptation activities occur in countries when, and for as long as, funding from global and regional sources is available" - although such a judgement overlooks the innate resilience of societies in many PICs (e.g. Lauer et al. 2013, McMillen et al. 2014).

At least on paper, such external funding for adaptation should be increasingly available. At the 2009 Copenhagen Summit, developed countries pledged to mobilise US $\$ 100$ billion $^{3}$ in climate finance per year by 2020 , as well as $\$ 30$ billion in fast-start finance for the period from 2010 through 2012 (UNFCCC 2009). These targets are for both mitigation and adaptation, and cover public and private finance; it is contested how much funding should be from public sources and how much should be channelled to adaptation (Castro and Betzold 2016), although the 2015 Paris Agreement stipulates "a balance between adaptation and mitigation" (UNFCCC 2015).

\footnotetext{
2 I thank Paul Mitchell for raising this point.

${ }^{3}$ All figures are in constant 2013 US\$ unless specified otherwise.
} 
For particularly vulnerable countries, support with adaptation is more important than mitigation, and adaptation finance largely comes from public sources (Buchner et al. 2014): as official development assistance, or aid (Ayers and Abeysinghe 2013). Indeed, operationally, there are good reasons for harnessing synergies between development and adaptation to climate change and making use of existing funding channels (Ayers and Huq 2009). Nonetheless, from a policy perspective, there is a difference between aid and adaptation finance, the latter resulting from an obligation under the principle of "common but differentiated responsibilities and respective capabilities" laid out in the United Nations Framework Convention on Climate Change (UNFCCC 1992, Ayers and Abeysinghe 2013). For developing countries, including PICs, this principle is fundamental, and emphasises the need for resources that are "new and additional" to existing aid budgets (Maclellan 2011, Maclellan and Meads Barry Coats 2012, Robinson and Dornan 2015).

Leaving the question of additionality aside, to what extent does adaptation aid reach the PICs? This paper examines adaptation aid as reported in the Creditor Reporting System (CRS) of the Organisation for Economic Cooperation and Development (OECD) from 2010 through 2014. Using descriptive statistics, it maps adaptation aid to PICs, focusing on the overall volume of adaptation aid, its allocation across recipients and across sectors, as well as its sources.

Although the present analysis is only a first step towards a more detailed understanding of adaptation aid flows in the Pacific, it indicates some trends:

- First, adaptation aid to PICs is only a small share of global adaptation aid as well as of total development aid to the region.

- Second, adaptation aid comes from only a small number of mostly bilateral donors, and is, third, distributed unevenly among PICs, in total adaptation aid, on a per capita basis as well as in percent of overall development aid.

- Finally, adaptation aid in the Pacific has steadily declined from a high in 2011. Australia as the single largest provider of adaptation aid is driving this decline; it reduced its support for adaptation from $\$ 169$ million in 2011 to less than $\$ 40$ million in 2014. 
To enable the PICs to adapt to climate change, donors do not only need to scale up their adaptation aid; importantly, they also need to ensure that this aid is used as effectively and efficiently as possible. Finally, better reporting is necessary for monitoring donor pledges and tracking adaptation aid on the ground.

\section{Data on Adaptation Aid}

Comparable and comprehensive data on adaptation aid are hard to come by, not least because it is contested what should count as adaptation aid. In practice, many development projects have an adaptation component - and many adaptation projects have a development component (e.g. Ayers and Huq 2009, Ayers and Abeysinghe 2013).

This paper relies on the "Rio Marker for adaptation", or adaptation marker, introduced by the OECD in 2010. Since then, donors have been required to indicate for every aid project whether it is relevant for adaptation, that is, if "it intends to reduce the vulnerability of human or natural systems to the impacts of climate change and climaterelated risks, by maintaining or increasing adaptive capacity and resilience" (OECD 2011, p.4). The adaptation marker distinguishes between aid projects where adaptation is the principal purpose and aid projects where adaptation is a significant objective. For the former type of projects - in the following referred to as "principal adaptation projects" - adaptation is the fundamental purpose, while for the latter - "significant adaptation projects" - adaptation is important but not the main objective (OECD 2011, p.5).

Relying on the adaptation marker means relying on donors' self-reporting. This may be problematic, as donors tend to over-report and over-state the adaptation relevance of their aid (Michaelowa and Michaelowa 2011, Junghans and Harmeling 2012, AdaptationWatch 2015, Donner et al. 2016). The OECD Creditor Reporting System (CRS) further includes only the Development Assistance Committee (DAC) donors and excludes some multilateral funding. These limitations notwithstanding, the OECD CRS has the most comprehensive coverage and provides comparable data across donors. Additionally, the OECD CRS contains detailed, project-level information; it is thus possible to examine not only overall levels of adaptation aid, but also for instance which 
recipients and sectors benefitted or through which channel (bilateral or multilateral) and as what type (grant or loan) aid is provided.

Only countries that are on the OECD DAC list of aid recipients are included in the OECD CRS. Sixteen countries and territories in the Pacific are on the DAC list: the fourteen sovereign Pacific Island Countries ${ }^{4}$ as well as the dependent territories of Tokelau and Wallis and Futuna (OECD 2015a). Regional programmes are also eligible for OECD DAC aid.

The paper uses disbursements. All figures were converted into constant 2013 US\$ with the help of the OECD Development Assistance Committee deflators (OECD 2015b).

\section{Results}

The following sections provide a detailed snapshot of adaptation aid flows to the PICs from 2010 through 2014. The analysis first examines the overall volume of adaptation aid to the region and the distribution across recipient countries. It then turns to the distribution across sectors, and finally focuses on the providers of adaptation aid.

\subsection{Overall Adaptation Aid Volume}

Between 2010 and 2014, the OECD DAC donors marked about $\$ 36$ billion of all their disbursed aid as relevant for adaptation. Of this, $\$ 705$ million, or just under 2 percent, went to PICs. This $\$ 705$ million in disbursed adaptation aid is somewhat below commitments, which amounted to just under \$1 billion. Adaptation aid to the Pacific, whether disbursements or commitments, is not only a small part of global adaptation aid, but also only a small part of overall development aid that went into the region. With a total of about $\$ 10.6$ billion in disbursements, the $\$ 705$ million of adaptation aid corresponds to 7 percent of all development aid disbursed to the Pacific, with more significant ( $\$ 461$ million, 65 percent of all adaptation aid) than principal ( $\$ 243$ million, 35 percent of all adaptation aid) adaptation activities (see figure 1).

\footnotetext{
4 These are: Cook Islands, Fiji, Kiribati, Marshall Islands, (Federated States of) Micronesia, Nauru, Niue, Palau, Papua New Guinea, Samoa, Solomon Islands, Tonga, Tuvalu and Vanuatu.
} 


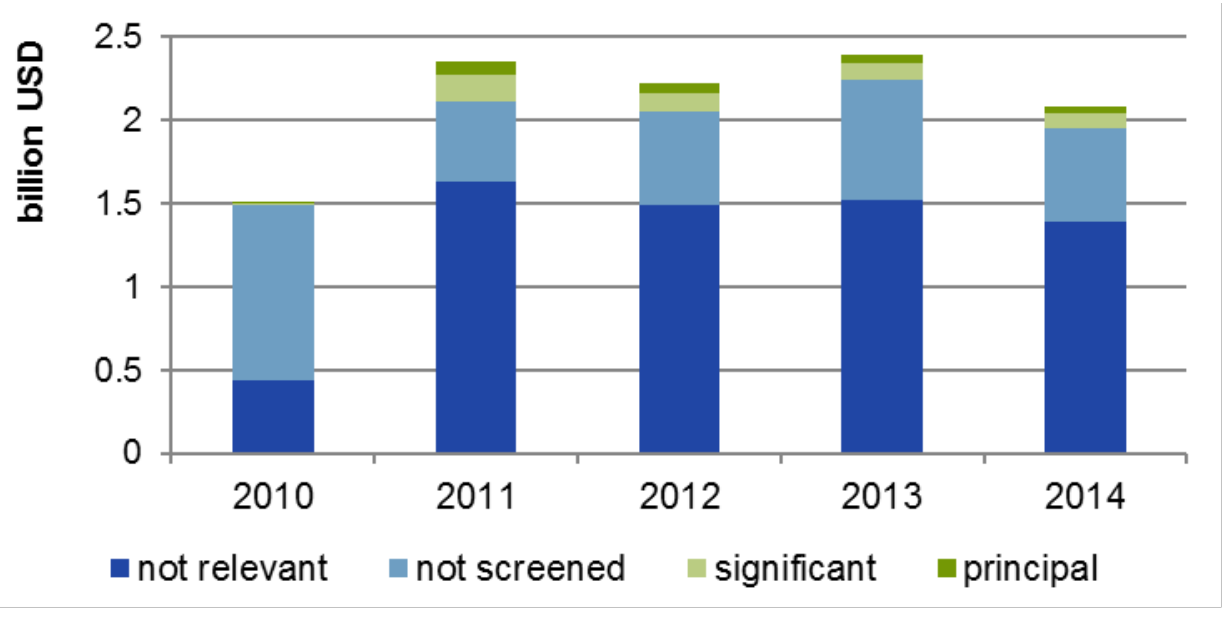

Figure 1: Aid to the Pacific by relevance to adaptation. Source: based on OECD CRS.

Figure 1 also shows that donors disbursed very little adaptation aid in 2010, as (a) not all donors systematically applied the adaptation marker right after its introduction and (b) it takes time for committed funds to be disbursed. In 2011, during the so-called faststart finance period, disbursed adaptation aid grew to $\$ 242$ million in 2011, but then steadily declined to $\$ 124$ million in 2014 . This decline is largely driven by drastic reductions in Australian support for adaptation in the region: while Australian adaptation aid in 2011 amounted to $\$ 169$ million, the figure for 2014 is only $\$ 39$ million.

From the short period of just five years for which the OECD has data, it is impossible to draw robust conclusions about time trends - aid flows tend to be volatile (Bulír and Hamann 2001, Bulíř and Hamann 2003). Nonetheless, the decrease in adaptation aid after 2011 is discouraging, all the more so as adaptation aid globally has increased in the same period, and further increases can be expected if donors heed their pledges for increased climate finance made in the lead-up to and at Paris (UNFCCC Secretariat 2015). Whether PICs can benefit from these new pledges remains to be seen.

While it is difficult to estimate how large the adaptation needs in the Pacific are, the roughly $\$ 141$ million disbursed per year is very likely insufficient, as is the about $\$ 200$ million committed per year. A report by the Asian Development Bank puts the adaptation cost for the Pacific region at about $\$ 447$ million every year until 2050 in its worst-case scenario. Even in the best-case scenario with significant global mitigation, 
annual average costs would be about $\$ 158$ million every year (Asian Development Bank 2013). Although the $\$ 141$ million per year disbursed in the five years under analysis seem nearly sufficient under the best-case scenario, there is little room for optimism for several reasons. First, it is doubtful that we will achieve ambitious mitigation; the current trends in global greenhouse gas emissions suggest otherwise (Le Quéré et al. 2015). Second, as the present analysis indicates (see later sections), not all aid that is marked as relevant for adaptation has a clear adaptation focus. The overall figure of $\$ 705$ million is thus a rather optimistic upper bound of actual adaptation aid flows to the Pacific. This is also true because, third, the figures here include both grants and loans, so part of the $\$ 705$ million will need to be paid back. While the OECD CRS does not include all donors and all flows, it seems that overall, adaptation aid to PICs is less than what is needed for the region to effectively cope with and adjust to climate change.

\subsection{Recipients of Adaptation Aid}

Who received how much of the $\$ 705$ million in adaptation aid? As figure 2 shows, adaptation aid was distributed unevenly among the 17 recipients - the 14 independent PICs, the territories of Tokelau and Wallis and Futuna as well as regional programmes. Similar results are obtained when looking at commitments rather than disbursements.

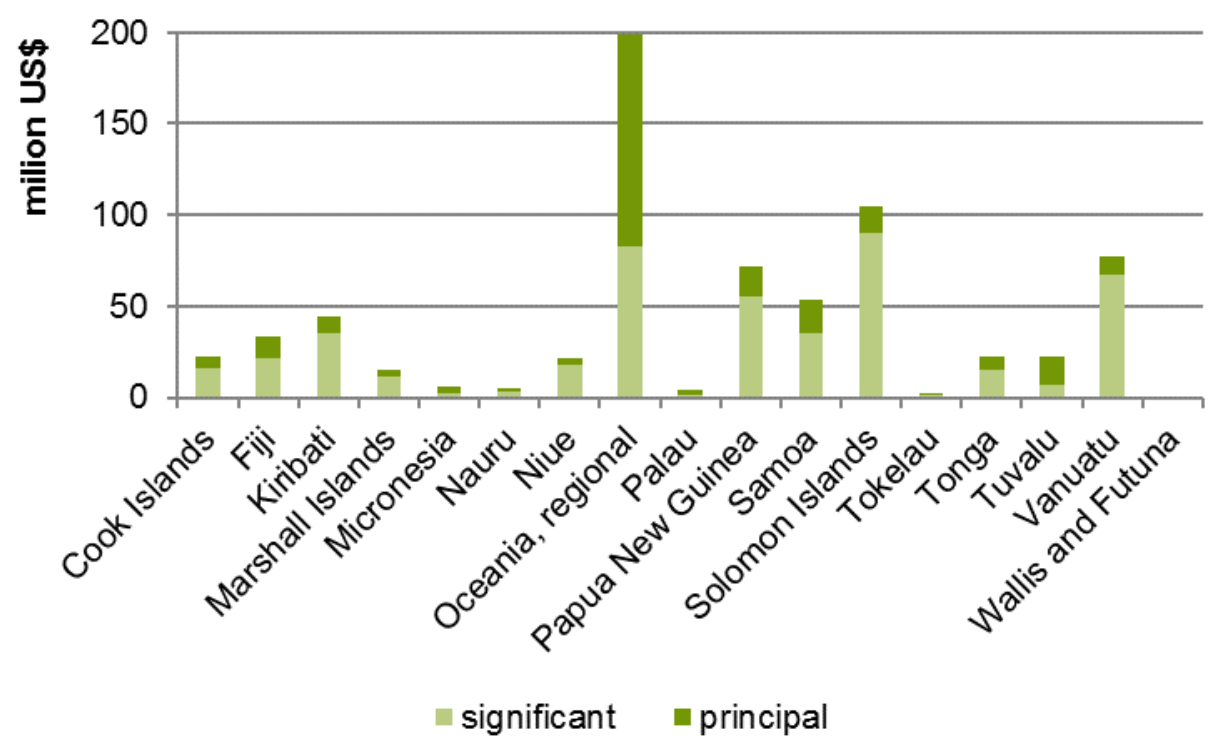

Figure 2: Adaptation aid to the Pacific, 2010 through 2014, by recipient.

Source: based on OECD CRS. 
The latter, regional programmes, received by far the largest share: over one quarter of all adaptation aid - \$199 million - targeted Oceania as a region, largely for principal adaptation projects ( $\$ 115$ million).

About half that sum, \$104 million, went to the Solomon Islands, the second largest recipient of adaptation aid in the Pacific. The large majority of that adaptation aid ( $\$ 90$ million) had adaptation as a significant co-benefit and not as its principal purpose. Vanuatu and Papua New Guinea also received sizeable shares of disbursed adaptation, with $\$ 77$ million and $\$ 72$ million, respectively. Again, much of this had adaptation as a co-benefit.

In terms of principal adaptation, Samoa is the second-largest recipient of adaptation aid after regional programmes, with $\$ 18$ million for principal adaptation aid projects, out of $\$ 53$ million total adaptation aid. This amount of principal adaptation aid is small relative to that received by regional programs ( $\$ 115$ million).

Yet, such comparisons mask important differences in population size across the PICs: in 2013, population size ranged from 7.4 million inhabitants in Papua New Guinea to just 1600 inhabitants in Niue and 1400 inhabitants in Tokelau. Figure 3 hence compares per capita adaptation aid across the PICs. ${ }^{5}$

On average, each Pacific Islander received $\$ 75$ in adaptation aid in the period under analysis; this number puts Pacific islanders at the top of per capita adaptation aid recipients globally - yet there are stark differences across islands. Especially inhabitants of the smallest countries are among the top recipients of per capita adaptation aid, in regional and global comparison (see Betzold and Weiler 2015).

By far the largest recipient of adaptation aid per capita is Niue, which is on the righthand axis in figure 3 below. Niue has been described as the "world's most aiddependent country" (Barnett 2008, p.33). As a country freely associated with New Zealand and with only around 1,500 inhabitants, Niue generally receives very high

\footnotetext{
5 Population data were taken from the United Nations Statistics Division (2015); from the Secretariat of the Pacific Community (2015) for Niue; from Government of Tokelau (2014) for Tokelau; and from the Institut d'émission d'outre-mer (2014) for Wallis and Futuna. To obtain adaptation aid per capita, the average population size for the period 2010 through 2014 was used.
} 
levels of (per capita) aid from New Zealand - and adaptation is no exception. Each Niuean received about $\$ 14,020$ in adaptation aid from 2010 through 2014, of which $\$ 11,602$ were for significant and $\$ 2,419$ for principal adaptation projects.

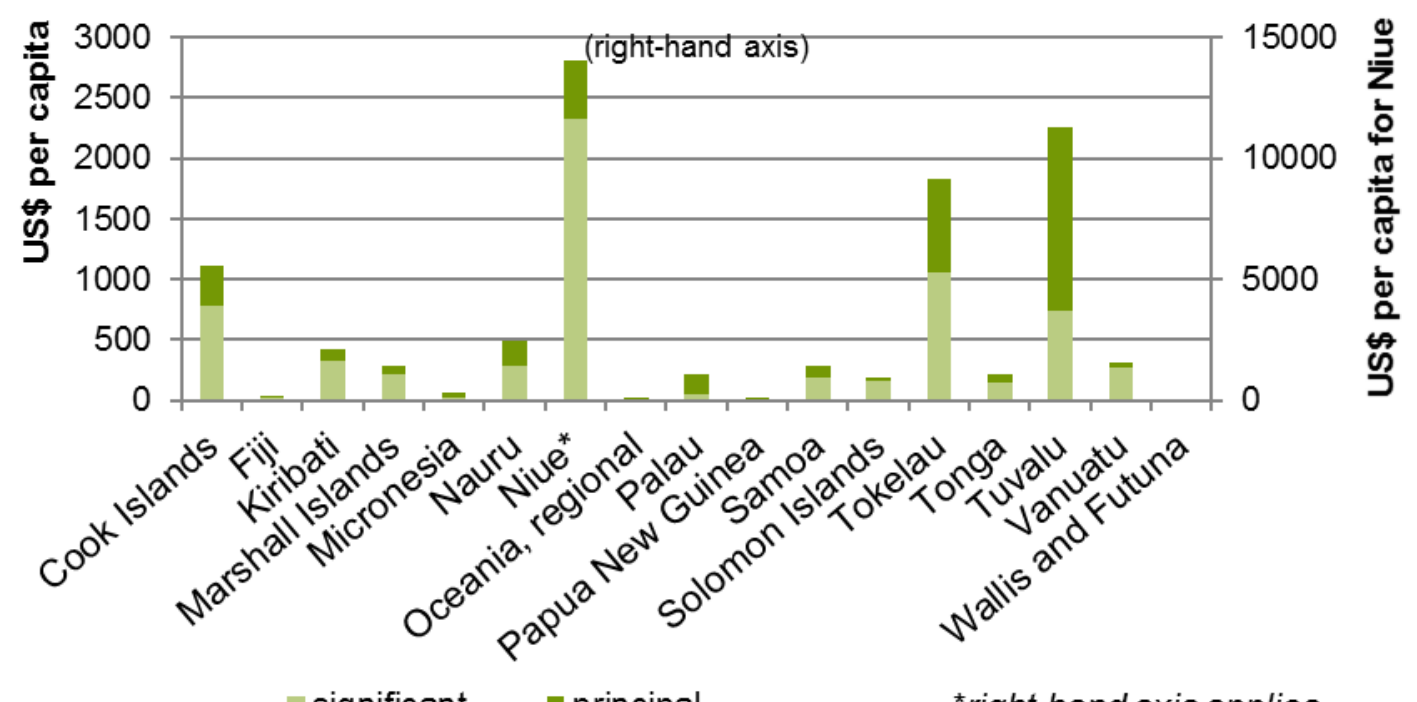

Figure 3: Adaptation aid to the Pacific per capita, 2010 through 2014, by recipient. Source: based on OECD CRS.

Far behind come Tuvaluans, who each received \$2,253 in adaptation aid from 2010 through 2014, of which $\$ 1,500$ was for principal adaptation. A large part of total adaptation aid provided to Tuvalu is associated with a single project, the Tuvalu Renewable Energy Projects funded by New Zealand. New Zealand committed \$17 million to this project, and already disbursed \$7 million. Given Tuvalu's population of just under 10,000 habitants, this project - marked as having both mitigation and adaptation as its principal purpose - translates into $\$ 726$ per Tuvaluan, and accounts for almost one third of all adaptation aid committed to Tuvalu in the period of analysis.

Tuvalu is followed by two other very small countries, Tokelau with $\$ 1,834$ for each of its ca. 1,400 inhabitants and the Cook Islands with $\$ 1,105$ for each of its ca. 20,000 inhabitants. In contrast, Nauru, Palau and Wallis and Futuna, while also very small with populations of ca. 10,000, 21,000 and 12,000, respectively, received per capita adaptation aid levels more in line with the larger countries: $\$ 489$ per capita in Nauru and \$215 per capita in Palau. Wallis and Futuna did not receive any adaptation aid, although the European Union committed \$2 million for one adaptation project repairing 
the energy system of the island after Cyclone Evan in 2013, which corresponds to $\$ 177$ per capita in Wallis and Futuna.

Not surprisingly, the largest countries (in terms of their population) - Papua New Guinea and Fiji - received the least adaptation aid on a per capita level. With a population of over 7 million, Papua New Guinea obtained $\$ 10$ adaptation aid per inhabitant, while Fiji, with a population of about 890,000 , received $\$ 38$ per inhabitant.

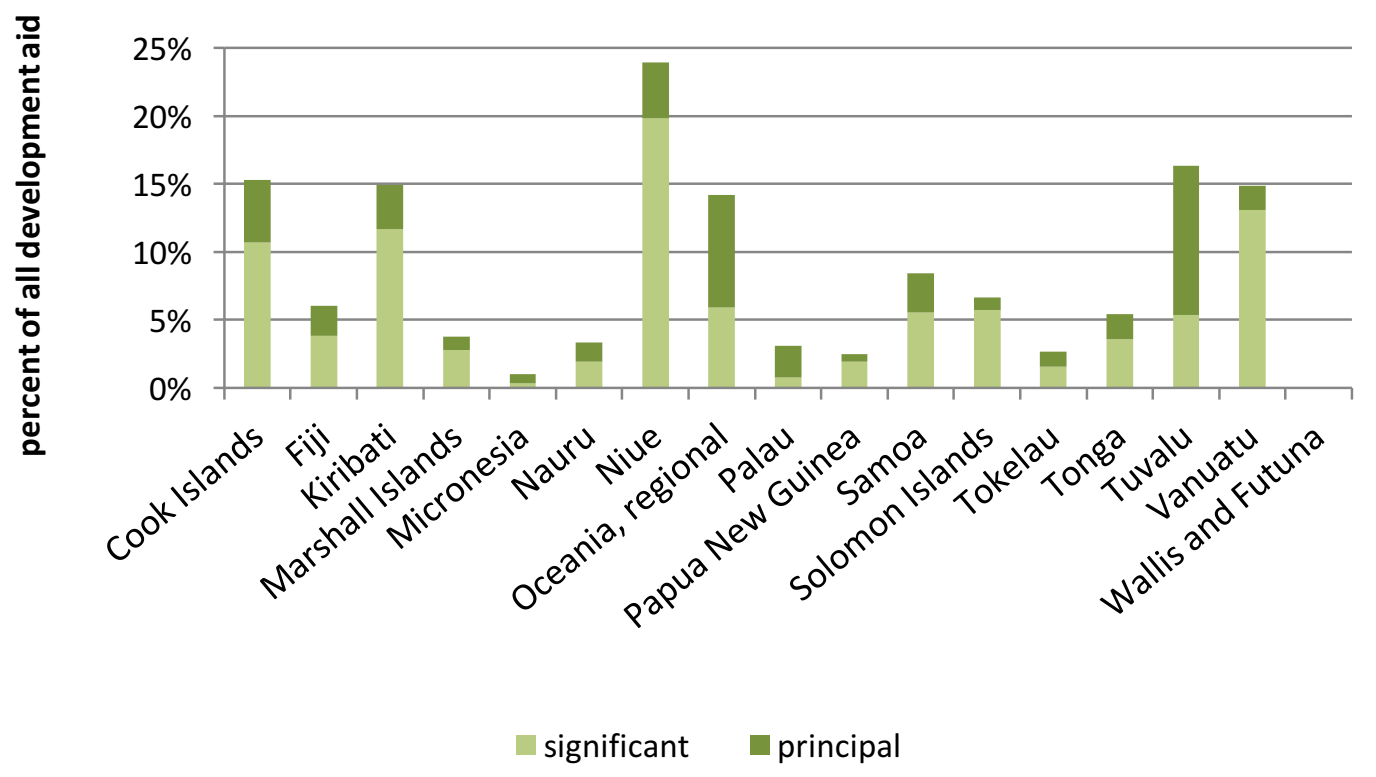

Figure 4: Adaptation aid to the Pacific, 2010 through 2014, in percent of all development aid to each country. Source: based on OECD CRS.

A somewhat different picture emerges when looking at how much of all development aid disbursed to a country was marked as relevant for adaptation (see figure 4). Again, Niue tops the list: of all aid disbursed to Niue between 2010 and 2014, 24 percent targeted adaptation. Niue is followed by Tuvalu, the Cook Islands, Kiribati, Vanuatu and regional programmes; for all of these countries or programmes, about 15 percent of all disbursed adaptation aid had an adaptation objective.

Percentages are lower when only taking into account principal adaptation aid. Only in Tuvalu (11 percent) and regional programmes (8 percent) did principal adaptation aid comprise at least 5 percent of all aid these countries received. On average, less than 3 percent of all aid targeted adaptation as a principal purpose, while the percentage increases to 8 percent when also taking into account significant adaptation. 
In five PICs - Nauru, Palau, Tokelau (3 percent each), Papua New Guinea (2 percent) and Micronesia (1 percent) - 3 percent or less of all aid targeted adaptation, as either a significant or the principal purpose. To some extent, these low figures may be due to donors not applying the Rio markers consistently, or may also reflect government priorities, at least in the case of Papua New Guinea.

How adaptation aid is allocated across recipients receives growing academic attention (e.g. Barrett 2014, Betzold and Weiler 2015, Robertsen et al. 2015). While this paper does not attempt a systematic explanation of the determinants of adaptation aid allocation in the Pacific, the above analysis gives us some indications.

First, the very small countries freely associated with or territory of New Zealand - that is, Niue, the Cook Islands and Tokelau - receive very high levels of adaptation aid per capita. They are, together with Tuvalu, the largest per capita recipients of adaptation aid. In contrast, other very small countries, including the dependent territory of Wallis and Futuna, receive low levels of adaptation aid per capita, partly because some of the financial support is not registered as official development assistance.

Second, single projects have a big impact, given the small population sizes and comparatively small amounts of funding. The renewable energy project in Tuvalu mentioned earlier accounts for one third of the country's adaptation aid. Other projects are even bigger. The largest project in terms of commitments is the Lapetasi Wharf Development Project in Port Vila, Vanuatu. ${ }^{6}$ Japan committed $\$ 62$ million as a loan to this infrastructure project, marked as having a significant adaptation objective, and has so far disbursed \$2.5 million. The adaptation component of these - and other, large and small - projects is not always clear and would require more detailed analysis going beyond the information available in the OECD CRS (see also sections 3.3 and 4 below). What is clear, however, is that large projects implemented in PICs significantly impact aggregate climate change adaptation flows as recorded in the OECD CRS.

Third, vulnerability matters: the literature as well as policy debates agree that vulnerable countries should be given priority access to adaptation funding (Barr et al.

\footnotetext{
${ }^{6}$ For more information on the project, see the Vanuatu Project Management Unit at http://vpmu.gov.vu/index.php/projects, or the press release by the Japanese International Cooperation Agency at http://www.jica.go.jp/english/news/press/2012/120613.html.
} 
2010, Grasso 2010). Yet to what extent funding reaches those most in need of support is unclear from the OECD data. While PICs share a common vulnerability to the adverse impacts of climate change, the degree of vulnerability varies between but also within PICs. The least developed PICs, communities in rural outer islands or women and children tend to be more vulnerable, but to what extent these groups benefit from aidfunded adaptation projects is unclear (see Maclellan and Meads, Barry Coats 2012).

\subsection{Adaptation Aid by Sector}

What is adaptation aid used for? Two projects were already highlighted - the renewable energy project in Tuvalu and the Lapetasi Wharf infrastructure project in Vanuatu. The OECD CRS categorises aid projects by sector. Figure 5 makes use of this categorisation. It shows that most adaptation projects related to general environmental protection: $\$ 191$ million, or 27 percent of the total, went into this category, overwhelmingly to projects where adaptation was the principal purpose ( $\$ 151$ million). Mostly, the projects under the category of general environmental protection focused on policy and administrative management (\$102 million) and research (\$71 million). 


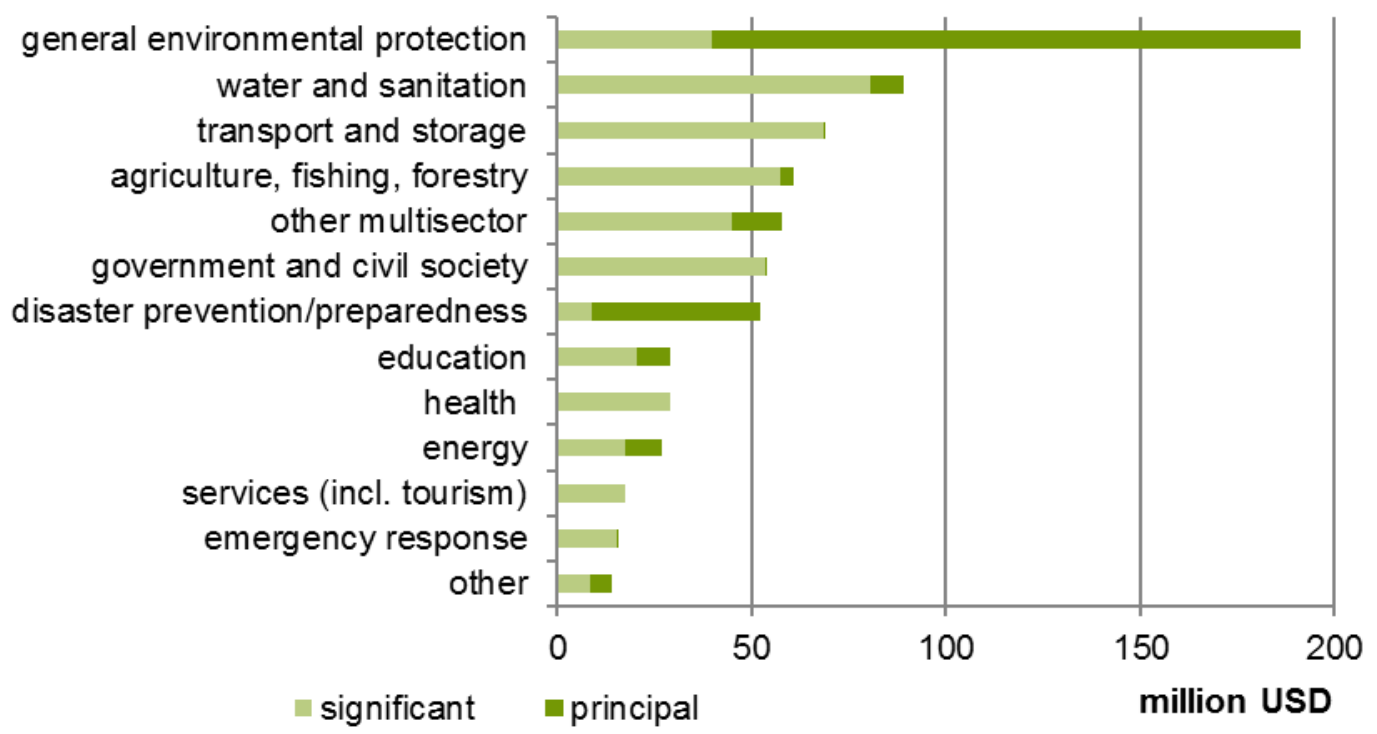

Figure 5: Adaptation aid to the Pacific, 2010 through 2014, by sector.

Source: based on OECD CRS.

Water and sanitation received $\$ 89$ million, largely for projects where adaptation was a co-benefit (\$81 million). Slightly lower amounts were disbursed for transport and storage ( $\$ 69$ million); agriculture, fishing and forestry ( $\$ 61$ million); other multisector projects ( $\$ 58$ million); government and civil society ( $\$ 54$ million); and disaster prevention and preparedness ( $\$ 52$ million). Only in the last category, disaster prevention and preparedness, did most projects focus on adaptation as principal purpose: over 80 percent of all adaptation aid disbursed to the sector targeted mainly adaptation (for global environmental protection, 79 percent went to principal adaptation projects).

What can we further conclude from this breakdown of adaptation aid by sector? While more detailed analyses beyond the OECD CRS would be helpful, two tentative conclusions may be drawn here. First, donors spend large amounts of funding on adaptation policy and planning. There is no doubt that appropriate legislation and national-level adaptation strategies are important in guiding local-level adaptation. Yet, national-level planning does not necessarily translate into local-level action, all the more so in archipelagic countries with disbursed populations. Implementation has 
historically been a problem in the Pacific (Duncan 2011). Beyond supporting policies and planning nationally, donors should also focus attention on the local level and ensure funding reaches communities (Nunn 2009, Nunn 2010).

Second, it is worth looking more closely at what donors count as adaptation aid - and to critically examine to what extent adaptation projects really have significant adaptation benefits. The Rio Markers are not mutually exclusive; donors can - and do - mark projects as relevant for both mitigation and adaptation. Yet it is questionable whether a mitigation project like the renewable energy project in Tuvalu automatically has direct adaptation benefits. The same can be said for other projects like the Lapetasi Wharf development. Unfortunately, not all entries in the OECD CRS are very informative and allow us to see why a donor has marked a specific project as relevant for adaptation. There is thus a danger that donors simply re-label and mislabel their general development aid, biasing efforts to measure and track adaptation aid (see Michaelowa and Michaelowa 2011, Junghans and Harmeling 2012, AdaptationWatch 2015, Donner et al. 2016).

\subsection{Providers of Adaptation Aid}

Finally, let us turn to the providers of adaptation aid. Figure 7 breaks down adaptation aid by channel - multilateral or bilateral - and by donor. As can be seen, the vast majority of adaptation aid to the region came from bilateral donors: out of the total \$705 million in adaptation aid disbursed, \$595 million (84 percent) came from bilateral donors, compared to $\$ 110$ million (16 percent) from multilateral donors. For principal adaptation aid, multilateral donors provided about one quarter ( $\$ 59$ million, 24 percent), the remainder ( $\$ 184$ million, 76 percent) coming from bilateral donors. Significant adaptation aid, in contrast, came almost exclusively from bilateral donors: 89 percent of all funding for significant adaptation projects ( $\$ 411$ million) were funded bilaterally, and only 11 percent (\$50 million) multilaterally.

The multilateral donors active in adaptation in the region are the European Union and two funds: the Adaptation Fund (AF) and the Climate Investment Funds (CIFs). The 
Global Environment Facility (GEF) committed \$53 million, but the OECD CRS reported no disbursements. ${ }^{7}$

The funding of these multilateral actors comes from bilateral donors, although the AF, established under the UNFCCC in 2001, also receives a share of the proceeds from the Clean Development Mechanism. The European Union was by far the largest multilateral actor; it disbursed $\$ 93$ million, with roughly equal shares to significant ( $\$ 50$ million) and principal adaptation (\$43 million). The remaining \$16 million of multilateral adaptation aid came almost exclusively from the AF; it disbursed $\$ 15$ million for significant adaptation. The CIFs, finally, have one adaptation window, the Pilot Program for Climate Resilience, which channels adaptation funding through the multilateral bank system to the Pacific. So far, only $\$ 730,000$ has been disbursed through this window.

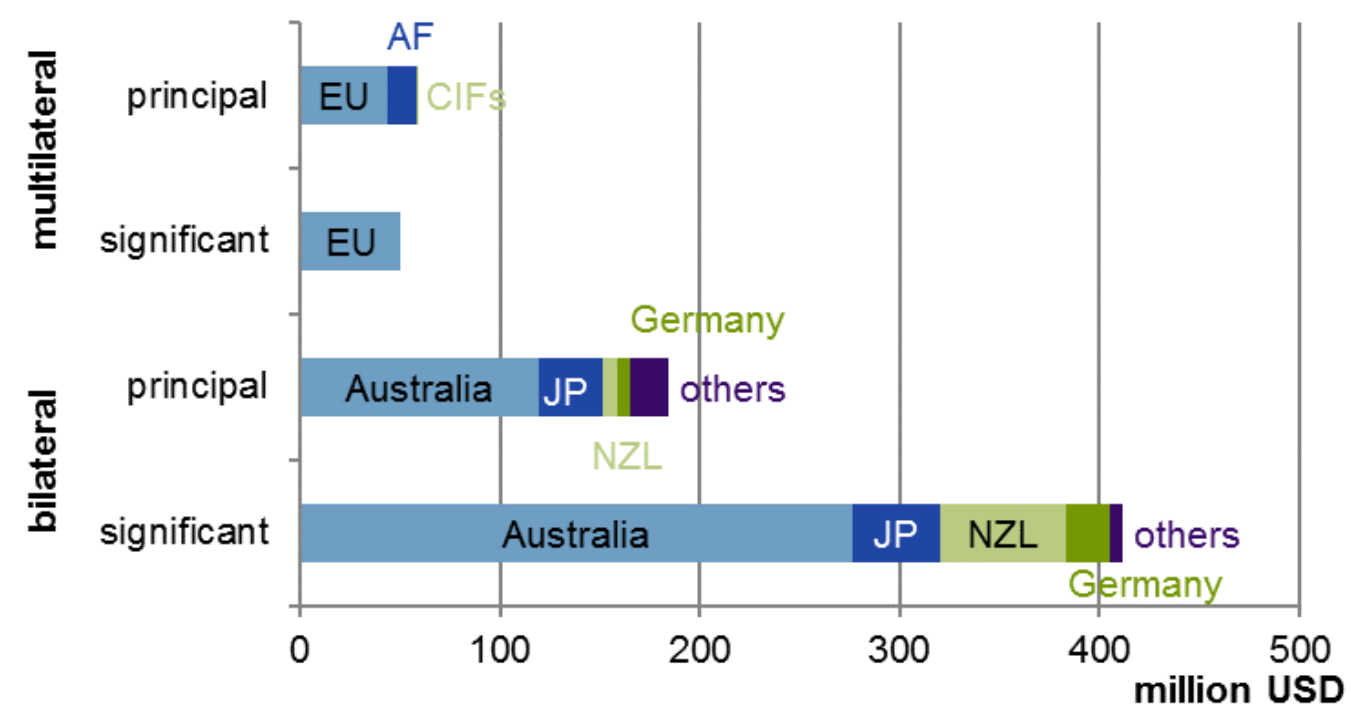

\section{$\mathrm{EU}=$ European Union; $\mathrm{AF}=$ Adaptation Fund; CIFs = Climate}

Investment Funds; JP = Japan; NZL = New Zealand

Figure 6: Providers of adaptation aid to the Pacific. Source: based on OECD CRS.

Among the bilateral donors, large neighbours - Australia, New Zealand and Japan were the key providers of funding, with Germany and some other countries disbursing relatively minor shares of total bilateral adaptation aid.

\footnotetext{
7 For further information on the multilateral funds, see https://www.adaptation-fund.org/ for the AF; https://www-cif.climateinvestmentfunds.org/fund/pilot-program-climate-resilience for the CIFs' Pilot Program for Climate Resilience; and https://www.thegef.org/gef/ for the GEF.
} 
Australia was by far the most important donor overall. It disbursed a total of $\$ 396$ million in adaptation aid - two thirds of all bilateral adaptation aid that came to the region. Of the $\$ 396$ million, about $\$ 276$ million (70 percent) had adaptation as a significant and \$119 million (30 percent) as the principal purpose. As already outlined in section 3.1, Australian adaptation aid steadily declined since 2011. While Australia disbursed 43 percent of its total adaptation aid for the 2010-14 period in 2011, less than 10 percent was disbursed in 2014.

Japan and New Zealand each provided about 13 percent of all bilateral adaptation aid, with $\$ 75$ million and $\$ 71$ million, respectively. Again, the majority of this aid went to significant projects (58 and 89 percent, respectively).

Germany, finally, was the fourth-largest bilateral donor of adaptation aid. It disbursed $\$ 28$ million adaptation aid, about as much as all other bilateral donors together. These other donors - the United States, Korea, France, Italy, Spain, Finland, Austria, Switzerland, the United Kingdom and Sweden - jointly contributed \$25 million. These funds went largely to principal adaptation projects, as a result of the United States, which disbursed $\$ 9$ million to principal adaptation, but did not fund significant adaptation projects in the region.

Is there also a pattern in terms of which donors supported which country? Figure 8 further breaks down adaptation aid. It lists per recipient how much percent of all its adaptation aid came from which donor. For readability, the smaller bilateral donors and the $\mathrm{AF}$ and CIFs are lumped together. 


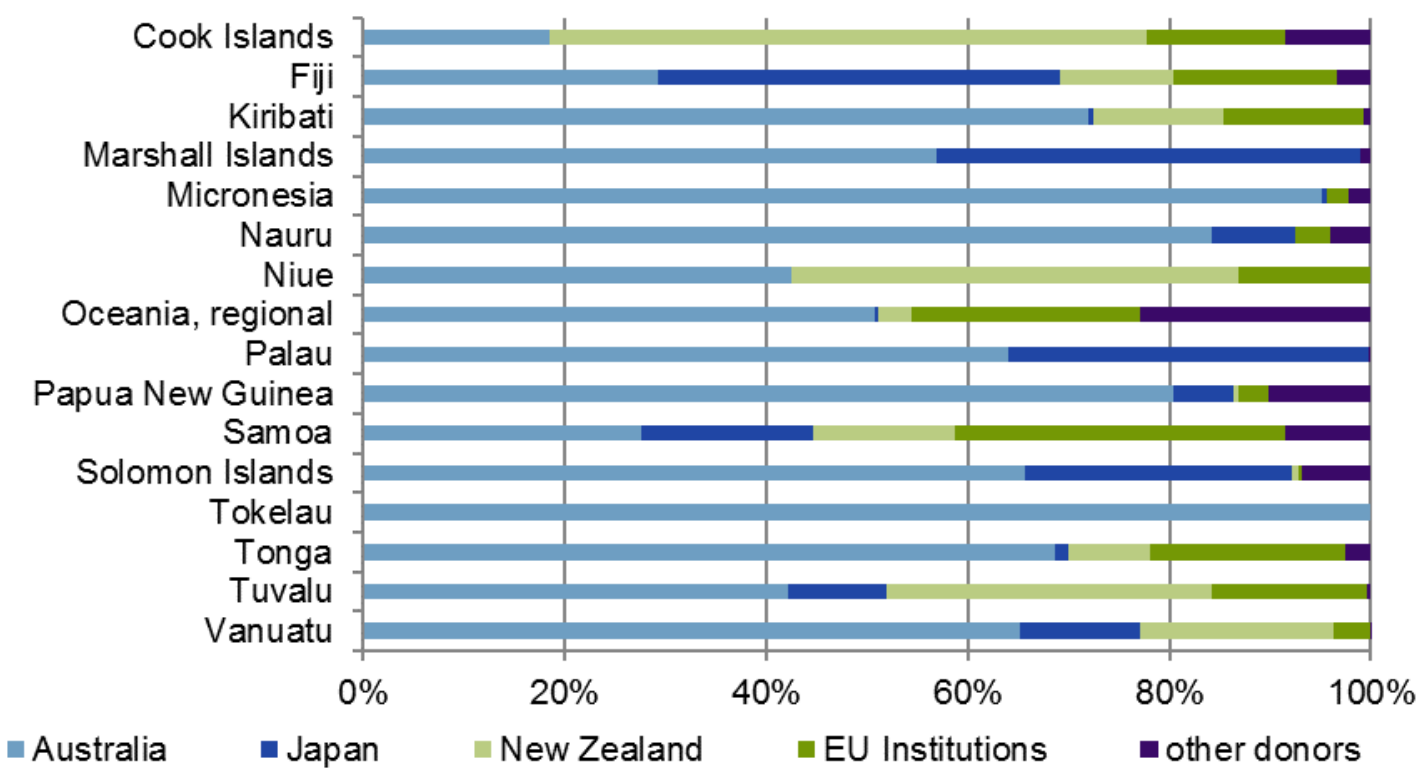

Figure 7: Adaptation aid to the Pacific by recipient and by donor, in percent. Source: based on OECD CRS.

Australia supported adaptation in all the PICs, and indeed provided the majority of adaptation funding in all but four countries (the Cook Islands, Fiji, Niue and Samoa). In Tokelau, all adaptation aid came from Australia, though Tokelau is a dependent territory of New Zealand. This may be because New Zealand did not systematically apply the Rio Markers or provided funding through channels other than aid. Micronesia similarly depended for almost all of its adaptation aid on Australia, which provided 95 percent of all adaptation aid disbursed to Micronesia.

Japan was a similarly active adaptation funder in the region, disbursing funds to all PICs except Tokelau and Niue. Japan was the largest funder of adaptation in Fiji, where it provided 40 percent of all adaptation aid, and also provided significant funding in the Marshall Islands (42 percent), Palau (36 percent) and the Solomon Islands (26 percent).

New Zealand as the third largest provider of adaptation aid was also present in most PICs, and is in particular a key partner for the Cook Islands and Niue, which are both freely associated with New Zealand and which received 59 and 40 percent, respectively, of all their adaptation aid from New Zealand. 
The European Union contributed to adaptation in almost all PICs, with the exception of the Marshall Islands, Palau and Tokelau. EU funding was of particular importance in Samoa, where one third of all adaptation funding comes from the European Union. Regional programmes and Tonga also obtained considerable portions of their adaptation aid from the European Union, at 23 and 19 percent, respectively.

Finally, other bilateral and multilateral donors only played minor roles in most PICs, although they provided sizeable shares for regional adaptation programmes (23 percent) as well as for adaptation in Papua New Guinea (10 percent), the Cook Islands, Samoa ( 9 percent each) and the Solomon Islands (7 percent).

Adaptation aid comes from only a small number of actors, most notably Australia. Australia is not only the single largest donor in the region, but also by far the largest donor in several countries. Indeed, PICs tend to receive most of their adaptation aid from just one or two donors. On the one hand, this eases the administrative burden as there are not too many different reporting requirements. On the other hand, this is a potential risk when donor priorities change and programmes are cut, as the Australian example makes clear. Australia's adaptation aid has steadily declined; while it provided $\$ 169$ million in 2011, this figure went down to just \$39 million in $2014 .^{8}$

Multilateral funding has to date played a comparatively small role in Pacific adaptation. Multilateral funds are often particularly difficult to access, with high bureaucratic and administrative hurdles (Maclellan 2011, Robinson and Dornan 2015). Developing countries therefore successfully pushed for direct access at the Green Climate Fund, which may increase the level of multilateral funding in the future. The Green Climate Fund became operational in 2015 and is expected to channel a significant portion of global climate finance and notably adaptation finance: it reserves 50 percent of its funding for adaptation, and 50 percent of its adaptation funding for small island developing states, least developed countries and African states (Green Climate Fund 2014). Among the first approved projects, two are located the Pacific: one in Fiji (Green Climate Fund 2015) and one in Tuvalu (Green Climate Fund 2016).

\footnotetext{
${ }^{8}$ Australia did not apply the Rio marker for adaptation in 2010.
} 


\section{Conclusion}

This paper has made use of the adaptation marker used in the OECD CRS to map adaptation aid disbursed to the Pacific between 2010 and 2014. Specifically, the paper has examined the overall volume of adaptation aid disbursed to the region, its distribution across recipient countries, its use across sectors as well as its sources. The analysis indicates that donors - most importantly Australia - collectively provided about $\$ 705$ million adaptation aid to the region. This total volume of adaptation aid is distributed unequally across PICs. There are stark contrasts in how much adaptation aid individual PICs receive, in total adaptation aid, on a per capita basis as well as in percent of overall development aid.

Although Pacific Islanders overall are among the top recipients of adaptation aid per capita globally (Robinson and Dornan 2015), the total volume of $\$ 705$ million is only a small share of global adaptation aid, as well as a small share of overall development aid that came to the Pacific. Additionally, while adaptation aid has gone up globally, it has declined in the Pacific since 2011, because of the steady decline in Australian adaptation aid to the region. To what extent the disbursed funding for adaptation is enough to meet demand for assistance with adaptation is questionable, especially when taking into account that funds are distributed unequally and that this figure includes loans as well as grants, and projects with unclear adaptation benefits.

Indeed, to what extent adaptation aid in practice leads to effective adaptation and increased resilience is unclear and worth further in-depth analysis. The focus on policy development for instance may not necessarily lead to more adaptation activities on the ground. Similarly, the adaptation benefits of some projects are not immediately evident from the information provided in the OECD CRS. More detailed analyses would not only make it possible to identify potential over-reporting and mislabelling - which has been found to be rampant in the OECD CRS (AdaptationWatch 2015, Donner et al. 2016) and hence to obtain a more precise picture of adaptation aid in the Pacific; they would also help get a better understanding of how aid is spent on the ground and which groups within recipient countries benefit from adaptation aid. Finally, such detailed analyses can also assess aid effectiveness and examine when and why adaptation works - as well as when and why it does not (Nunn 2013). 
Clearly, money is not the only answer, and more money does not automatically lead to more - or better - adaptation (Barnett 2008, Nunn 2013). Nonetheless, successful adaptation in the Pacific and elsewhere requires substantial and predictable funding. Donors should not only scale up their support for adaptation; they should also ensure that funding is used as wisely as possible, in line with recipients' needs and priorities. Finally, donors need to agree clearer definitions and reporting guidelines so that adaptation funding can be monitored and evaluated. 


\section{References}

AdaptationWatch (2015) Toward Mutual Accountability: The 2015 Adaptation Finance Transparency Gap Report. AdaptationWatch.org.

Agard, J. and E. L. F. Schipper (2014). Annex II: Glossary. Climate Change 2014: Impacts, Adaptation, and Vulnerability. Contribution of Working Group II to the Fifth Assessment Report of the Intergovernmental Panel of Climate Change. V. R. Barros et al. Cambridge, United Kingdom and New York, NY, USA, Cambridge University Press: 1757-1776.

Asian Development Bank (2013) The Economics of Climate Change in the Pacific. Asian Development Bank Mandaluyong City, Philippines.

Ayers, J. M. and A. C. Abeysinghe (2013). International Aid and Adaptation to Climate Change. The Handbook of Global Climate and Environment Policy. R. Falkner, John Wiley \& Sons: 486-506.

Ayers, J. M. and S. Huq (2009). Supporting Adaptation to Climate Change: What Role for Official Development Assistance? Development Policy Review 27(6): 675-692.

Barnett, J. (2005). Titanic States? Impacts and Responses to Climate Change in the Pacific Islands. Journal of International Affairs 59(1): 203-219.

Barnett, J. (2008). The Effect of Aid on Capacity to Adapt to Climate Change: Insights from Niue. Political Science 60(1): 31-45.

Barr, R., et al. (2010). Adaptation Investments: A Resource Allocation Framework. Mitigation and Adaptation Strategies for Global Change 15: 843-858.

Barrett, S. (2014). Subnational Climate Justice? Adaptation Finance Distribution and Climate Vulnerability. World Development 58: 130-142.

Betzold, C. and F. Weiler (2015). Who Gets Aid for Adaptation to Climate Change, and Why?, Paper presented at the workshop 'Climate Finance: Taking Stock, Future Directions for Policy and Research', Lund University, April 2015. 
Buchner, B., et al. (2014). The Global Landscape of Climate Finance 2014, Climate Policy Initiative Report.

Bulíř, A. and A. J. Hamann (2001). How Volatile and Unpredictable Are Aid Flows, and What Are the Policy Implications? , International Monetary Fund Working Paper. $01 / 167$.

Bulíř, A. and A. J. Hamann (2003). Aid Volatility: An Empirical Assessment. IMF Staff Papers 50(1): 64-89.

Castro, P. and C. Betzold (2016). Climate Finance after the Paris Agreement. New Directions or More of the Same? Bonn, Stiftung Entwicklung und Frieden. Global Governance Spotlight. 3/2016.

Donner, S. D., et al. (2016). Measuring and Tracking the Flow of Climate Change Adaptation Aid to the Developing World. Environmental Research Letters 11(5): 054006.

Duncan, R., Ed. (2011). The Political Economy of Economic Reform in the Pacific. Pacific Studies Series. Manila, Asian Development Bank.

Government of Tokelau (2014). 2013 Population Count, Available at http://www.tokelau.org.nz/Tokelau+Government/Government+Departments/Office+o $\underline{\mathrm{f}+\text { the }+ \text { Council+for+the+Ongoing }+ \text { Government+OCOG/Tokelau+National+Statistics+Offi }}$ ce/2013+Population+Count.html.

Grasso, M. (2010). Justice in Funding Adaptation under the International Climate Change Regime. Dordrecht etc., Springer.

Green Climate Fund (2014). Decisions of the Board - Sixth Meeting of the Board, 1921February 2014. Document number GCF/B.06/18

Green Climate Fund (2015). Decisions of the Board - Eleventh meeting of the Board, 2 5 November 2015, Document number GCF/B.11/24. 
Green Climate Fund (2016). "GCF Board approves projects worth $\$ 250 M$ and prepares for leadership transition." Retrieved 6 July 2016, from

http://www.greenclimate.fund/documents/20182/38417/release_GCF_2016_0630_B1 3.pdf.

Institut d'émission d'outre-mer (2014). Rapports Annuels de Wallis et Futuna. Available at http://www.ieom.fr/wallis-et-futuna/publications/rapports-annuels-38/.

Junghans, L. and S. Harmeling (2012). Different Tales from Different Countries: A First Assessment of the OECD 'Adaptation Marker', Germanwatch Briefing Paper.

Lauer, M., et al. (2013). Globalization, Pacific Islands and the Paradox of Resilience. Global Environmental Change 23: 40-50.

Lazrus, H. (2012). Sea Change: Island Communities and Climate Change. Annual Review of Anthropology 41: 285-301.

Le Quéré, C., et al. (2015). Global Carbon Budget 2015. Earth System Science Data 7: 349-396.

Maclellan, N. (2011). Improving Access to Climate Finance for the Pacific Islands, Lowy Institute for International Policy.

Maclellan, N. and S. Meads Barry Coats (2012) Owning Adaptation in the Pacific: Strengthening Governance of Climate Adaptation Finance. Oxfam Research Report McMillen, H. L., et al. (2014). Small Islands, Valuable Insights: Systems of Customary Resource Use and Resilience to Climate Change in the Pacific. Ecology and Society 19(4). Michaelowa, A. and K. Michaelowa (2011). Coding Error or Statistical Embellishment? The Political Economy of Reporting Climate Aid. World Development 39(11): 2010-2020. Nunn, P. D. (2009). Responding to the Challenges of Climate Change in the Pacific Islands: Management and Technological Imperatives. Climate Research 40: 211-231. 
Nunn, P. D. (2010). Bridging the Gulf Between Science and Society: Imperatives for Minimizing Societal Disruption from Climate Change in the Pacific. Adaptation and Mitigation Strategies for Climate Change. A. Sumi et al. Tokyo Berlin Heidelberg New York, Springer: 233-248.

Nunn, P. D. (2013). The End of the Pacific? Effects of Sea Level Rise on Pacific Island Livelihoods. Singapore Journal of Tropical Geography 34(2): 143-171.

Nurse, L. A., et al. (2014). Small Islands. Climate Change 2014: Impacts, Adaptation, and Vulnerability. Part B: Regional Aspects. Contribution of Working Group II to the Fifth Assessment Report of the Intergovernmental Panel on Climate Change. V. R. Barros et al. Cambridge and New York, Cambridge University Press: 1613-1654.

OECD (2011). "Handbook on the OECD-DAC Climate Markers." Retrieved 10 September 2014, from http://www.oecd.org/dac/stats/48785310.pdf.

OECD (2015a). "History of DAC Lists of aid recipient countries." Retrieved 11 February 2016, from

http://www.oecd.org/dac/stats/historyofdaclistsofaidrecipientcountries.htm.

OECD (2015b). "Information Note on the DAC Deflators." Retrieved 11 February 2016.

Robertsen, J., et al. (2015). Determinants Of The Flow Of Bilateral Adaptation-Related Climate Change Financing To Sub-Saharan African Countries, LICOS Discussion Paper 373/2015. Catholic University Leuven.

Robinson, S.-a. and M. Dornan (2015). International Financing for Climate Change Adaptation in Small Island Developing States, unpublished manuscript.

Secretariat of the Pacific Community (2015). National Minimum Development Indicators Version 2.0. Available at http://www.spc.int/nmdi/population.

UNFCCC (1992). United Nations Framework Convention on Climate Change, Document number FCCC/INFORMAL/84.

UNFCCC (2009). Copenhagen Accord, Document number FCCC/CP/2009/11/Add.1. UNFCCC (2015). Paris Agreement, Document number FCCC/CP/2015/L.9/Rev.1. 
UNFCCC Secretariat (2015). "List of Recent Climate Funding Announcements." Retrieved 6 July 2016, from http://newsroom.unfccc.int/financial-flows/list-of-recent-climatefunding-announcements/.

United Nations Statistics Division (2015). Exchange Rates and Population. Available at http://unstats.un.org/unsd/snaama/dnlList.asp.

Weir, T. and D. Orcherton (2013). Climate Change Issues on the Pacific Islands: An Overview. Climate-Smart Technologies. W. L. Filho et al. Berlin and Heidelberg, SpringerVerlag: 51-64. 